\title{
BMJ Open How do GPs in Switzerland perceive their patients' satisfaction and expectations? An observational study
}

\author{
Paul Sebo, ${ }^{1}$ François R Herrmann, ${ }^{2}$ Dagmar M Haller ${ }^{1,3,4}$
}

To cite: Sebo $P$, Herrmann FR, Haller DM. How do GPs in Switzerland perceive their patients' satisfaction and expectations? An observational study. BMJ Open 2015;5:e007085. doi:10.1136/bmjopen-2014007085

- Prepublication history for this paper is available online. To view these files please visit the journal online (http://dx.doi.org/10.1136/ bmjopen-2014-007085)

Received 9 November 2014 Revised 11 May 2015 Accepted 13 May 2015

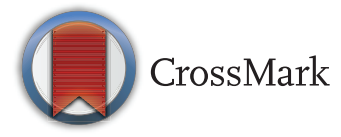

${ }^{1}$ Primary Care Unit, Faculty of Medicine, University of Geneva, Geneva, Switzerland ${ }^{2}$ Geriatrics Division, Department of Internal Medicine, Rehabilitation and Geriatrics, Geneva University Hospitals, Geneva,

Switzerland

${ }^{3}$ Department of Community, Primary Care and Emergency Medicine, Geneva University Hospitals, Geneva,

Switzerland

${ }^{4}$ Department of Pediatrics, Geneva University Hospitals, Geneva, Switzerland

Correspondence to Dr Paul Sebo; paulsebo@hotmail.com

\section{ABSTRACT}

Objectives: To assess doctors' perceptions of their patients' satisfaction and expectations in primary care. Study design: Cross-sectional study using questionnaires completed by general practitioners (GPs) and their patients.

Setting: Primary care practices in Geneva, Switzerland.

Participants: 23 GPs from a random list of 75 GPs practising in the canton of Geneva (participation rate $31 \%$ ), who each recruited between 50 and 100 consecutive patients coming to the practice for a scheduled medical consultation, leading to a total of 1637 patients (participation rate: $97 \%$, women: $63 \%$, mean age: 54 years). Patient exclusion criteria were: new patients, those consulting in an emergency situation or suffering from disorders affecting their ability to consent, and those who did not speak French.

Main outcome measures: Patients satisfaction with and expectations from the care they received in this practice; GPs perceptions of their patient's satisfaction and expectations.

Results: GPs underestimated all patient satisfaction items ( $p<0.001$ for all items) whereas they

overestimated their expectations, except for equipment (laboratory and X-ray) and some accessibility items. In a multivariate analysis to assess which GP factors were associated with correct assessment of their patients' views, only GPs' certification status was a significant factor.

Conclusions: GPs tend to underestimate patients' satisfaction but overestimate their expectations in primary care. These findings may help GPs to understand patients' views in order to adequately meet their expectations and concerns.

\section{INTRODUCTION}

Patients' satisfaction is considered as an important indicator of health quality. ${ }^{1-3}$ It is a key factor in the global assessment of health services, because it may influence crucial outcomes, such as adherence with treatment and medical costs. ${ }^{4-6}$ The assessment of healthcare services using patients'

\section{Strengths and limitations of this study}

- Previous studies have shown that general practitioners (GPS) seem poor at accurately perceiving their patients' satisfaction level with general practice, but, to our knowledge, no study has ever compared patients' expectations with the way their GPs perceive them.

- This is, to our knowledge, the first study to assess how accurately GPs are able to perceive their patients' views, both about their satisfaction levels and their expectations.

- The results showed that GPs underestimated all patient satisfaction items whereas they overestimated their expectations, except for equipment (laboratory and X-ray) and some accessibility items. These findings may help GPs to understand patients' views in order to adequately meet their expectations and concerns.

- This study was carried out only in one urban region, the Geneva area. The results that we obtained could be relatively different in another region of Switzerland or in another country.

satisfaction is generally well accepted by general practitioners (GPs). ${ }^{2}$ GPs are therefore advised to identify lack of satisfaction among their patients. Negative evaluations may help doctors to better address patients' concerns and improve quality of care. Yet, patients and GPs do not always agree on what constitutes good general practice and on the priorities to be given to different indicators of quality care. ${ }^{7-9}$ Overall, doctors seem poor at accurately perceiving their patients' satisfaction level with general practice. $^{10-14}$

As patients' satisfaction seems to increase when their expectations are addressed by their GP, GPs are also advised to take into account patients' expectations. ${ }^{15}$ Little is known, however, about GPs' ability to perceive what patients most commonly expect from them. A study showed that patients' expectations on over half of 40 aspects of general practice differed significantly from 
what GPs thought their patients were expecting. ${ }^{7}$ However, recruitment of the doctors and patients occurred independently. Therefore GPs' responses were not directly compared to those of their own patients, potentially limiting the interpretation of the results. To our knowledge, no study has ever compared patients' expectations with the way their GPs perceive them.

Our objective was thus to assess whether GPs are able to accurately perceive their patients' satisfaction with and expectations from the care GPs provide.

\section{METHODS}

\section{Recruitment of the doctors and the patients}

This study was part of a larger project to evaluate patients' satisfaction and expectations from primary care in Geneva, Switzerland. This was a cross-sectional questionnaire-based study taking place in 2011 in general practices in Geneva.

A random sample of 75 GPs, from the list of all GPs practising in the canton, was invited to participate by post, using simple random sampling, in order to include 25 GPs in the study (expected participation rate: $33 \%$ ). If they did not respond to the written invitation, the doctors were personally contacted by phone 2 or 3 weeks later. They were asked to recruit between 50 and 100 consecutive patients coming to the practice for a planned consultation. To take part in the study, patients had to be older than 15 years, understand and write French and have a planned appointment with the doctor; all new patients and those suffering from disorders affecting their ability to consent were excluded.

\section{Data collection}

Patients were provided with oral and written information and, following consent, were asked to complete a questionnaire containing demographic questions, and questions about their satisfaction level with and expectations from their GPs. The self-administered anonymous questionnaire had to be completed in the waiting room of the practice, before or after the consultation and deposited in a closed box on the desk. The questionnaire was pretested in a GP's practice (PS). The respondents (20 patients and 8 GPs) provided general feedback on the questionnaire and the cover letter, as well as comments on the content and wording of individual questions, as a result of which some questions were modified accordingly. Finally, we pretested the new version of the questionnaire. We also readministrated the same questionnaire to a small number of participants at a 2-week interval to make sure the questionnaire was reliable over time.

GPs were also asked to complete an anonymous questionnaire containing general questions (age, sex, certification in general internal medicine (in Switzerland, most GPs are certified in general internal medicine but under certain conditions, doctors who are not certified can nevertheless practice as GPs), location of the practice, number of GPs and employees in the practice, average working-hours per week, average working-years since certification and average working-years in the current practice) and questions about their perceptions of patients' satisfaction level and expectations.

\section{Measurement instruments}

Patient satisfaction was assessed using the Europep questionnaire, validated in French. ${ }^{16-18}$ For this project, we focused on six questions assessing organisational aspects of the healthcare provided by GPs: helpfulness of staff, getting an appointment to suit the patient, getting through to the practice on the telephone, being able to speak to the doctor on the telephone, waiting time in the waiting room and providing quick services for urgent health problems. The response format was a fivepoint Likert scale ranging from 'poor' to 'excellent'.

Patients' expectations were assessed using 14 items: 5 items exploring accessibility and availability (waiting time deemed acceptable in the waiting room, waiting time deemed acceptable to get an appointment for urgent/non urgent health problems, to be able to speak to the GP on telephone, number of interruptions of the consultation related to phone calls deemed acceptable), two items related to equipment (importance of having a laboratory/X-ray equipment in the practice), three items exploring appearance and cleanliness (importance of wearing a white coat during the consultation, importance of the GP washing his or her hands, importance of the cleanliness of the practice), and finally five items assessing accessibility and availability outside office opening hours (importance of the GP being accessible by phone $24 \mathrm{~h}$ a day/during the day on weekends, importance of the GP making home visits / making home visits $24 \mathrm{~h}$ a day / during the day on weekends). These items were selected following a literature review and discussions within the research team. The questions about the importance given to the different aspects of follow-up were assessed on a five-point Likert scale ranging from 'not at all important' to 'extremely important'.

GPs' perceptions of patients' satisfaction level and expectations were assessed in the same way, using the same scales. In other words, GPs were asked to imagine how their patients would have responded and to score the items accordingly.

\section{Sample size justification and statistical analysis}

Considering that 25 GPs would be included in the study and 50-100 patients per doctor asked to complete the questionnaire, we expected to receive 1250-2500 questionnaires. The sample size was estimated in order to measure the prevalence $(50 \%)$ of the 'patient expectations' items (categorical data) with a margin of error less than 5\%. From computation, a sample size of 400 patients would have been sufficient, but we had to take the cluster effect into account, related to the fact that the patients were recruited in different practices (adjustment taking into account the artificial decrease of the 
variance of measures collected in the same practice). Using an intraclass correlation of 0.025 (estimate based on published data and our personal experience) ${ }^{19}$ and the assumption that 100 patients could be recruited in each practice, the inflation factor was 3.48 and our total sample size estimate was 1392 patients $(400 \times 3.48)$.

Mean scores and SDs were used to summarise data regarding satisfaction and importance given to the different aspects of follow-up, whereas we computed median scores and IQRs for the other items exploring patients' expectations. Paired t tests and Wilcoxon signed-rank tests were used, where appropriate, to compare patients' views with GPs' perceptions. Finally, multiple logistic regression models were carried out to identify which doctor factors were independently associated with the ability to correctly evaluate patients' satisfaction, assessed either as overall satisfaction or as the mean of all satisfaction items. These models allow for intragroup correlation, relaxing the usual requirement that the observations be independent. The dependent variable was a binary variable coded as 1 when the difference between patient and doctor satisfaction was considered small $(<0.5)$ or 0 when the difference was considered large ( $\geq 0.5$, ie, the GP failed to identify patients' views).

\section{RESULTS}

Among the 75 GPs located in the Geneva area who were contacted at random, $31 \%(n=23)$ agreed to participate in the study (men: $61 \%$, mean age: 50 years, minimummaximum: $35-65$ years), corresponding to $92 \%$ of the expected number of participants. Twenty $(87 \%)$ were certified in general internal medicine, $12(52 \%)$ had their medical office located in a city (ie, urban setting with population $>15000$ ); the majority had solo or duo practices (39\% and 35\%, respectively); and almost two-thirds employed medical assistants or administrative staff. On average, they were working $38.6 \mathrm{~h}$ per week (SD 11.1, minimum-maximum 20-60), 4.7 days per week (SD 0.6, minimum-maximum 3.5-5.5) and were relatively experienced doctors (average number of working-years since certification: 10.5 (SD 10.1, minimum-maximum 1.5-31), average number of working-years in the current medical practice: 8.6 (SD 8.6, minimum-maximum 1.5-31)). It is worth noting that the sample of 23 GPs who agreed to participate seems to be representative of the study population $(\mathrm{n}=650)$, as mean age (50 vs 53 years) and sex (men: $61 \%$ in the two groups) are similar.

1637 patients provided consent to participate in the study, corresponding to 71 patients per doctor on average, well above the expected sample size $(n=1392)$. Note that only 45 patients refused to participate (women: 60\%, mean age: 64 years), the resulting participation rate being above $97 \%$.

Table 1 presents the patients' sociodemographic characteristics. They were predominantly women $(63 \%)$ and aged 54 years on average (SD 18 years).
Table 2 compares patients' satisfaction with GPs' perceptions of their patients' satisfaction. On average, patients were very satisfied, though the item concerning the waiting time in the waiting room was rated slightly less favourably. For all items, patients' scores were higher than those estimated by the GPs ( $p$ value $<0.001$ for all items).

Table 3 presents the results for expectation items in the same way (patients' scores and GPs' perception scores). The pattern obtained through the comparison between patients and doctors' scores was slightly more complex for expectation items. GPs tended to

\begin{tabular}{|c|c|c|}
\hline Characteristics & $n / N^{*}$ & Per cent \\
\hline Female & $981 / 1563$ & 62.8 \\
\hline \multicolumn{3}{|l|}{ Age group (years) } \\
\hline$<25$ & $97 / 1566$ & 6.2 \\
\hline $25-65$ & $974 / 1566$ & 62.2 \\
\hline$>65$ & $495 / 1566$ & 31.6 \\
\hline \multicolumn{3}{|l|}{ Marital status } \\
\hline Single & $386 / 1579$ & 24.5 \\
\hline Married & $783 / 1579$ & 49.6 \\
\hline Divorced or separated & $276 / 1579$ & 17.5 \\
\hline Widowed & $134 / 1579$ & 8.5 \\
\hline \multicolumn{3}{|l|}{ Nationality } \\
\hline Swiss & $1163 / 1569$ & 74.1 \\
\hline Italian & $92 / 1569$ & 5.9 \\
\hline French & $89 / 1569$ & 5.7 \\
\hline Portuguese & $57 / 1569$ & 3.6 \\
\hline Spanish & $34 / 1569$ & 2.2 \\
\hline Other $(<2 \%)$ & $134 / 1569$ & 8.5 \\
\hline \multicolumn{3}{|l|}{ Completed training } \\
\hline No training & $63 / 1505$ & 4.2 \\
\hline Compulsory schooling & $149 / 1505$ & 9.9 \\
\hline Apprenticeship & $506 / 1505$ & 33.6 \\
\hline $\begin{array}{l}\text { Baccalaureate or diploma from } \\
\text { intermediate school }\end{array}$ & $340 / 1505$ & 22.6 \\
\hline University, FIT, UAS & $447 / 1505$ & 29.7 \\
\hline \multicolumn{3}{|l|}{ Work status } \\
\hline Student & $85 / 1569$ & 5.4 \\
\hline Occupational activity & $648 / 1569$ & 41.3 \\
\hline Retired & $467 / 1569$ & 29.8 \\
\hline $\begin{array}{l}\text { Recipient of unemployment or } \\
\text { invalidity insurance }\end{array}$ & $133 / 1569$ & 8.4 \\
\hline $\begin{array}{l}\text { Other (mainly house-wife/ } \\
\text { husband and without } \\
\text { employment) }\end{array}$ & $236 / 1569$ & 15.1 \\
\hline \multicolumn{3}{|l|}{ General health status } \\
\hline Excellent or very good & $449 / 1571$ & 28.6 \\
\hline Good & $848 / 1571$ & 54.0 \\
\hline Moderate or poor & $274 / 1571$ & 17.5 \\
\hline \multicolumn{3}{|c|}{ Number of consultations in the past 6 months } \\
\hline $1-2$ & $676 / 1571$ & 43.0 \\
\hline $3-4$ & $491 / 1571$ & 31.3 \\
\hline $5-6$ & $266 / 1571$ & 16.9 \\
\hline$\geq 7$ & $138 / 1571$ & 8.8 \\
\hline
\end{tabular}




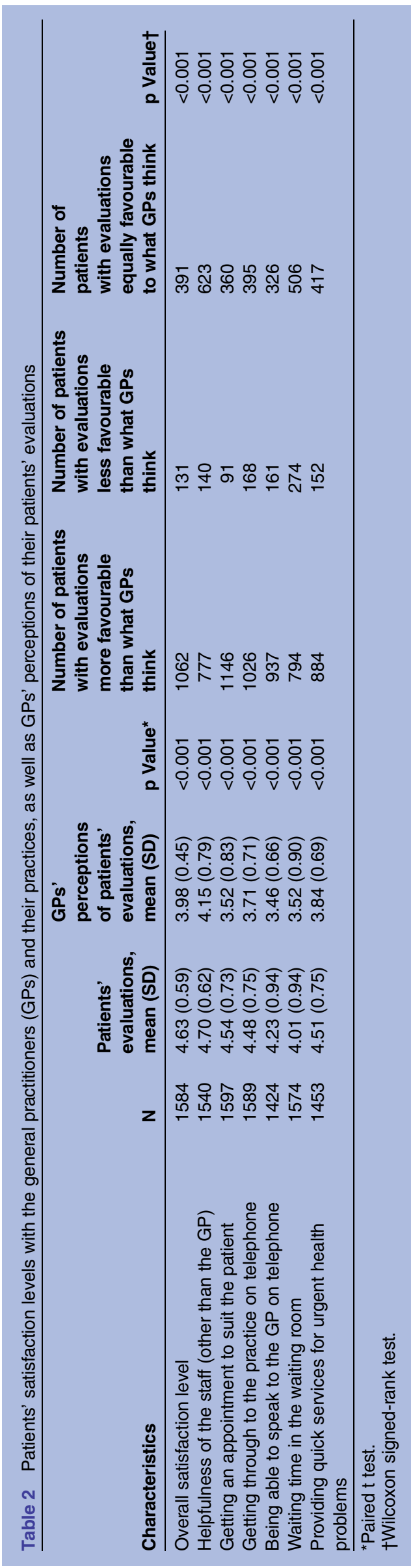

overestimate their patients' views, except for equipment (laboratory and X-ray), and some accessibility and availability items (providing quick services for urgent health problems, getting through to the practice on telephone and interruption of the consultation because of phone calls). Note that the vast majority of these differences were statistically significant.

Finally, among GPs' characteristics, only certification status was independently associated with the ability of the GPs to correctly evaluate patients' scores (table 4). Compared to certified doctors, those who were uncertified had $40 \%$ and $60 \%$ less chance to correctly evaluate their patients' overall satisfaction and their patients' mean of all satisfaction items, respectively, after taking all other doctor characteristics into account (ie, $40 \%$ and $60 \%$ less chance that the difference between doctors and patients' scores were less than 0.5).

\section{DISCUSSION}

We found that, on the whole, GPs tended to underestimate their patients' satisfaction levels. These findings are in accordance with previous studies, which found that doctors were poor at accurately estimating their patients' satisfaction level, and tend to underestimate how positive patients are about their care. ${ }^{10-14}$ Interestingly, GPs also tend to be more critical than patients about the quality of care they provide. ${ }^{1420}$ There are several explanations for these findings. Patients and GPs do not always agree on what constitutes good general practice and important consultation skills, and on the priorities to be given to different indicators of quality care. ${ }^{7-9}$ As satisfaction may depend on expectations being met, ${ }^{15}$ any discrepancies between patients and GPs regarding patients' expectations could, at least in part, explain why GPs are unable to accurately perceive their patients' satisfaction. Another explanation could be that doctors prefer to be modest in their estimation and more critical of their skills than patients, for fear of being disappointed. The fact that GPs in our study had a tendency to overestimate their patients' expectations, except for equipment and some accessibility and availability items, is consistent with this hypothesis and could therefore explain why patients were more satisfied than doctors believed they were.

In multivariate analysis, only GPs' certification status was associated with the ability to correctly evaluate patients' satisfaction. The finding that uncertified GPs had less ability to correctly evaluate patients' views could be due to the role of chance, as they represented a relatively small subgroup. Alternatively, uncertified GPs might have (voluntarily or not) altered their perception, because they thought that their patients were less satisfied, as they were uncertified; certified doctors usually acquired certification after training in university clinics where organisational aspects of care are often discussed; finally, as certification usually means additional training and qualifications, certified doctors could be also more skilled at accurately estimating their patients' satisfaction level. 
Table 3 Patients' expectations towards the general practitioners (GPs) and their practices, as well as GPs' perceptions of their patients' expectations

\begin{tabular}{|c|c|c|c|c|c|c|c|c|}
\hline Characteristics & $\mathbf{N}$ & $\begin{array}{l}\text { Patients' } \\
\text { expectations, mean } \\
\text { (SD) or median (IQR) }\end{array}$ & $\begin{array}{l}\text { GPs' perceptions of } \\
\text { patients' expectations, } \\
\text { mean (SD) or median } \\
\text { (IQR) }\end{array}$ & p Value* & $\begin{array}{l}\text { Number of patients with } \\
\text { higher expectations } \\
\text { than what GPs think }\end{array}$ & $\begin{array}{l}\text { Number of patients } \\
\text { with lower expectations } \\
\text { than what GPs think }\end{array}$ & $\begin{array}{l}\text { Number of patients with } \\
\text { equally high } \\
\text { expectations as what } \\
\text { GPs think }\end{array}$ & p Value \\
\hline $\begin{array}{l}\text { Importance of having a } \\
\text { laboratory in the practice }\end{array}$ & 1282 & $3.44(1.53)$ & $3.20(1.12)$ & $<0.001$ & 624 & 402 & 256 & $<0.001$ \\
\hline $\begin{array}{l}\text { Importance of having } \mathrm{X} \text {-ray } \\
\text { equipment in the practice }\end{array}$ & 1284 & $2.82(1.59)$ & $2.72(1.13)$ & 0.02 & 519 & 457 & 308 & 0.04 \\
\hline $\begin{array}{l}\text { Importance of wearing a white } \\
\text { coat during the consultation }\end{array}$ & 1437 & $2.60(1.65)$ & $3.27(0.84)$ & $<0.001$ & 401 & 821 & 215 & $<0.001$ \\
\hline $\begin{array}{l}\text { Importance of the GP washing } \\
\text { his or her hands }\end{array}$ & 1524 & $4.59(0.90)$ & $4.75(0.67)$ & $<0.001$ & 432 & 414 & 678 & 0.21 \\
\hline $\begin{array}{l}\text { Importance of the cleanliness } \\
\text { of the practice }\end{array}$ & 1545 & $4.63(0.75)$ & $4.74(0.44)$ & $<0.001$ & 302 & 324 & 919 & 0.07 \\
\hline $\begin{array}{l}\text { Importance of the GP being } \\
\text { accessible by phone } 24 \mathrm{~h} \text { a day }\end{array}$ & 1396 & 2.15 (1.35) & $2.51(1.06)$ & $<0.001$ & 419 & 722 & 255 & $<0.001$ \\
\hline $\begin{array}{l}\text { Importance of the GP being } \\
\text { accessible by phone during the } \\
\text { day on the weekend }\end{array}$ & 1346 & 2.09 (1.32) & $2.85(1.10)$ & $<0.001$ & 309 & 827 & 210 & $<0.001$ \\
\hline $\begin{array}{l}\text { Importance of the GP making } \\
\text { home visits }\end{array}$ & 1489 & $2.91(1.46)$ & $3.95(0.93)$ & $<0.001$ & 260 & 915 & 314 & $<0.001$ \\
\hline $\begin{array}{l}\text { Importance of the GP making } \\
\text { home visits } 24 \mathrm{~h} \text { a day }\end{array}$ & 1385 & $1.73(1.14)$ & $2.04(1.18)$ & $<0.001$ & 334 & 613 & 438 & $<0.001$ \\
\hline $\begin{array}{l}\text { Importance of the GP making } \\
\text { home visits during the day on } \\
\text { weekends }\end{array}$ & 1473 & $1.80(1.18)$ & 2.60 (1.09) & $<0.001$ & 292 & 938 & 243 & $<0.001$ \\
\hline $\begin{array}{l}\text { Waiting time deemed } \\
\text { acceptable in the waiting room } \neq\end{array}$ & 1600 & $4(2)$ & $4(1)$ & NA & 494 & 632 & 474 & 0.01 \\
\hline $\begin{array}{l}\text { Waiting time deemed } \\
\text { acceptable to get an } \\
\text { appointment for non urgent } \\
\text { health problems§ }\end{array}$ & 1595 & $5(2)$ & $5(2)$ & NA & 645 & 658 & 292 & 0.32 \\
\hline $\begin{array}{l}\text { Waiting time deemed } \\
\text { acceptable to get an } \\
\text { appointment for urgent health } \\
\text { problems }\end{array}$ & 1584 & $2(1)$ & $2(1)$ & NA & 553 & 275 & 756 & $<0.001$ \\
\hline $\begin{array}{l}\text { Waiting time deemed } \\
\text { acceptable to be able to speak } \\
\text { to the GP on telephone }\end{array}$ & 1562 & $3(1)$ & $3(0)$ & NA & 667 & 329 & 566 & $<0.001$ \\
\hline $\begin{array}{l}\text { Number of interruptions related } \\
\text { to phone calls during the } \\
\text { consultation deemed } \\
\text { acceptablet† }\end{array}$ & 1609 & $1(1)$ & $1(0)$ & NA & 518 & 175 & 916 & $<0.001$ \\
\hline \multicolumn{9}{|c|}{ 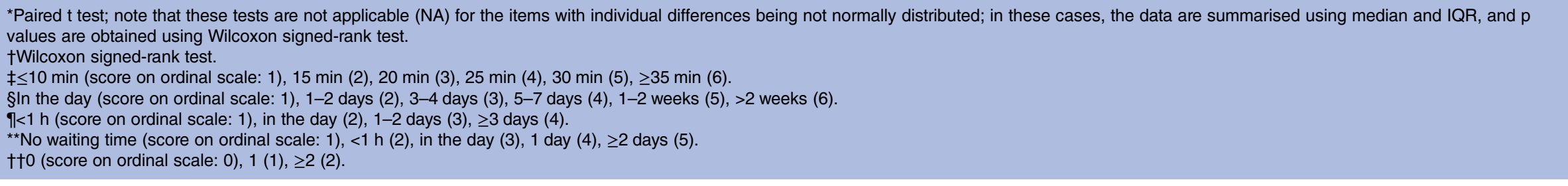 } \\
\hline
\end{tabular}


Table 4 General practitioners' (GPs) characteristics independently associated with the ability of the GPs to correctly evaluate patients' scores (multivariate analysis*); $\mathrm{N}=1637$ patients in $23 \mathrm{GP}$ clusters

\begin{tabular}{|c|c|c|c|c|}
\hline GPs' characteristics & $\begin{array}{l}\text { OR for difference in overall } \\
\text { satisfaction }(95 \% \mathrm{Cl})\end{array}$ & p Value & $\begin{array}{l}\text { OR for difference in mean of } \\
\text { all satisfaction items }(95 \% \mathrm{Cl})\end{array}$ & p Value \\
\hline \multicolumn{5}{|l|}{ Gender } \\
\hline Women & 1.0 & & & \\
\hline Men & $1.0(0.6$ to 1.9$)$ & 0.96 & $0.8(0.3$ to 2.0$)$ & 0.58 \\
\hline \multicolumn{5}{|l|}{ Age group (years) } \\
\hline$\leq 40$ & 1.0 & & & \\
\hline $41-50$ & $1.2(0.5$ to 2.6$)$ & 0.73 & $1.5(0.4$ to 5.0$)$ & 0.54 \\
\hline$\geq 51$ & $0.8(0.2$ to 2.6$)$ & 0.69 & $1.8(0.4$ to 7.9$)$ & 0.41 \\
\hline \multicolumn{5}{|l|}{ Certification } \\
\hline Yes & 1.0 & & & \\
\hline No & $0.6(0.3$ to 0.9$)$ & 0.04 & $0.4(0.2$ to 0.9$)$ & 0.02 \\
\hline \multicolumn{5}{|l|}{ Location of practice } \\
\hline Urban & 1.0 & & & \\
\hline Rural & $1.2(0.7$ to 1.9$)$ & 0.57 & $1.0(0.5$ to 1.9$)$ & 0.93 \\
\hline \multicolumn{5}{|l|}{ Type of practice } \\
\hline Solo & 1.0 & & & \\
\hline Duo & $0.9(0.5$ to 1.6$)$ & 0.75 & $0.9(0.5$ to 1.6$)$ & 0.66 \\
\hline Group & $1.3(0.7$ to 2.4$)$ & 0.37 & $0.8(0.3$ to 2.0$)$ & 0.57 \\
\hline \multicolumn{5}{|c|}{ Number of working years as GP (years) } \\
\hline$\leq 5$ & 1.0 & & & \\
\hline$>5$ & 1.1 (0.5 to 2.4$)$ & 0.78 & $1.0(0.4$ to 2.5$)$ & 0.92 \\
\hline
\end{tabular}

Although data comparing patients' and GPs' expectations are very important to the organisation of general practice, only few studies have addressed this question. ${ }^{7}$ In a study carried out in the Netherlands among 900 patients and 919 GPs, Vedsted $e t a l^{8}$ evaluated how differently they prioritise 40 aspects of care using the Europep questionnaire. In this study, though there was a general agreement in rankings, patients gave higher priorities than GPs to availability, accessibility and continuity of care. However, the study did not aim to assess how doctors perceive their own patients' expectations. Recruitment of the doctors and patients was carried out independently, meaning that follow-up of the patients was not provided by the GPs included in the study, which might limit the generalisability of the results. In another survey conducted in the Netherlands, Jung et $a l^{7}$ asked 455 GPs and 263 patients to give their opinions regarding good general practice. They showed that patients' and GPs' priorities regarding by the 40 aspects of care explored the Europep questionnaire differed significantly for 23 of the 40 aspects. In addition, the authors recruited a second sample of 237 GPs, who were asked to estimate patients' priorities. Similar results were obtained, as 23 aspects differed significantly. In this study, quick service in case of emergency was ranked as first priority for the three groups (patients, GPs and GPs about patients). Unfortunately, recruitment of the doctors and patients was, again, carried out independently. To our knowledge, no study so far aimed to compare patients' expectations with the way their own GPs perceive them.

\section{Limitations}

First, this study was carried out only in one urban region, the Geneva area. The results that we obtained could be relatively different in another region of Switzerland-for example, in a rural and/or a German speaking canton, or in another country. Second, new patients and those consulting in an emergency situation or who did not speak French were excluded from the study for practical reasons. These patients may have lower levels of satisfaction and different expectations as they are likely to have lower health or socioeconomic status than patients with a planned appointment and/or those who speak French. However, the participation rate was high $(>97 \%)$ and patients were enrolled consecutively, thus reducing the risk of selection bias. Third, though the doctors who were included in the study consisted of a random sample of those practising in the Geneva area, only one-third of those who were contacted agreed to participate; these doctors may have been more concerned with the study question and therefore more attentive to patients' expectations. Fourth, information bias was not excluded, since, though the questionnaires were anonymous, they were completed in the waiting room and therefore the patients could have overestimated their satisfaction levels in order to please their doctors. Fifth, as patients had the choice to complete the questionnaire before or after the consultation for practical reasons, patients' satisfaction could be influenced by the timing of completion of the questionnaire; by contrast, expectation items are probably not affected by the 
current consultation. Finally, the assessment of patients' expectations used a non-validated questionnaire. However, the selection of items for this questionnaire was based on a literature review and we chose a similar response format to that of the well-validated Europep questionnaire assessing patient satisfaction. In addition, the questionnaire was pretested among patients and GPs.

\section{Strengths}

This is, to our knowledge, the first study to assess how accurately GPs are able to perceive their patients' views, both about their satisfaction levels and their expectations. In addition, our findings were obtained from a large sample of consecutive patients, and GPs' recruitment was carried out at random. Also, the questions relative to the satisfaction levels were drawn from a previously well-validated questionnaire, which allowed us to make meaningful comparisons with other published studies. Finally, though selection bias cannot be completely excluded (participation rate only 30\% among the GPs), the very high participation rate among the patients $(>97 \%)$ reasonably allowed us to reduce the risk, taking into account the caveats about the exclusion criteria discussed above.

\section{Implications for clinical practice and research}

An explicit exploration of patients' expectations about the practice and their satisfaction could guide GPs in their daily clinical work and help them identify areas for improvement more specifically. Future research should provide guidance about how this can best be accomplished.

\section{Conclusion}

These findings highlight the relatively high satisfaction levels with GPs in the Geneva region, and suggest that GPs tend to underestimate their patients' satisfaction and overestimate their patients' expectations. As patient satisfaction and meeting patients' expectations seems to be related to better outcomes of general practice care, it is crucial for GPs to recognise patients' satisfaction (and dissatisfaction) with care and to adequately address their expectations. Improved communication between GPs and their patients about satisfaction and expectations would be of benefit both to GPs and to their patients.

Acknowledgements The authors would like to warmly thank all the doctors and patients who agreed to participate in this study, and Florence Siltz, our research assistant, who was responsible for the organisational aspects of the project.

Contributors PS conceptualised and designed the study, organised and managed participant recruitment and data collection, contributed to data analysis and interpretation, and wrote the first draft of the paper. FRH planned and carried out data analysis. DMH contributed to data interpretation and provided critical revision for important intellectual content. All authors read and approved the final manuscript.

Funding This project was jointly funded by the Swiss Medical Association (FMH) and the Swiss Academy of Medical Sciences (ASSM).

Competing interests None declared.

\section{Patient consent Obtained.}

Ethics approval The research protocol was approved by the local research ethics committee (reference: 09-01).

Provenance and peer review Not commissioned; externally peer reviewed.

Data sharing statement No additional data are available.

Transparency declaration The lead author (PS) affirms that this manuscript is an honest, accurate and transparent account of the study being reported.

Open Access This is an Open Access article distributed in accordance with the Creative Commons Attribution Non Commercial (CC BY-NC 4.0) license, which permits others to distribute, remix, adapt, build upon this work noncommercially, and license their derivative works on different terms, provided the original work is properly cited and the use is non-commercial. See: http:// creativecommons.org/licenses/by-nc/4.0/

\section{REFERENCES}

1. Richards T. Patients' priorities. BMJ 1999;318:277.

2. Bovier P, Künzi B, Stalder H. Qualité des soins en médecine de premier recours: 'à l'écoute de nos patients'. Rev Médicale Suisse 2006;80:2176-82.

3. Säilä T, Mattila E, Kaila M, et al. Measuring patient assessments of the quality of outpatient care: a systematic review. J Eval Clin Pract 2008; $14: 148-54$.

4. Winefield HR, Murrell TG, Clifford J. Process and outcomes in general practice consultations: problems in defining high quality care. Soc Sci Med 1982 1995;41:969-75.

5. Dang BN, Westbrook RA, Black WC, et al. Examining the link between patient satisfaction and adherence to HIV care: a structural equation model. PLOS ONE 2013;8:e54729.

6. Gu NY, Gai Y, Hay JW. The effect of patient satisfaction with pharmacist consultation on medication adherence: an instrumental variable approach. Pharm Pract 2008;6:201-10.

7. Jung HP, Wensing M, Grol R. What makes a good general practitioner: do patients and doctors have different views? Br J Gen Pract 1997:47:805-9.

8. Vedsted P, Mainz J, Lauritzen T, et al. Patient and GP agreement on aspects of general practice care. Fam Pract 2002;19:339-43.

9. Schieber AC, Kelly-Irving M, Rolland C, et al. Do doctors and patients agree on cardiovascular-risk management recommendations post-consultation? The INTERMEDE study. Br J Gen Pract 2011;61:e105-11.

10. Cannon B, Usherwood TP. General practice consultations-how well do doctors predict patient satisfaction? Aust Fam Physician 2007;36:185-6, 192.

11. Hall JA, Stein TS, Roter DL, et al. Inaccuracies in physicians perceptions of their patients. Med Care 1999;37:1164-8.

12. McKinstry B, Colthart I, Walker J. Can doctors predict patients' satisfaction and enablement? A cross-sectional observational study. Fam Pract 2006:23:240-5.

13. Zachariae R, Pedersen CG, Jensen AB, et al. Association of perceived physician communication style with patient satisfaction, distress, cancer-related self-efficacy, and perceived control over the disease. Br J Cancer 2003;88:658-65.

14. Jung HP, Wensing M, Olesen F, et al. Comparison of patients' and general practitioners' evaluations of general practice care. Qual Saf Health Care 2002;11:315-19.

15. Jung $H$, Wensing $M$, de Wilt A, et al. Comparison of patients preferences and evaluations regarding aspects of general practice care. Fam Pract 2000;17:236-42.

16. Grol R, Wensing M, Mainz J, et al. Patients' priorities with respect to general practice care: an international comparison. European Task Force on Patient Evaluations of General Practice (EUROPEP). Fam Pract 1999;16:4-11.

17. Grol R, Wensing M, Mainz J, et al. Patients in Europe evaluate general practice care: an international comparison. Br J Gen Pract 2000;50:882-7.

18. Grol R, Wensing MJP, Kersnik J. Patients evaluate general/family practice: the EUROPEP instrument. University Medical Centre, 2000.

19. Adams G, Gulliford MC, Ukoumunne OC, et al. Patterns of intra-cluster correlation from primary care research to inform study design and analysis. J Clin Epidemiol 2004;57:785-94.

20. Rashid A, Forman W, Jagger C, et al. Consultations in general practice: a comparison of patients' and doctors' satisfaction. $B M J$ 1989;299:1015-16. 